\title{
COACHING MODEL TO ENHANCE STUDENTS SELF-ACCESS LEARNING VIA DISTANCE LEARNING TELEVISION MANAGEMENT: A CASE STUDY OF ELEMENTARY SCHOOLS IN THAILAND
}

\author{
MARUT PATPHOL \\ Srinakharinwirot University, \\ Thailand \\ https://doi.org/10.37602/IJSSMR.2021.4211
}

\begin{abstract}
The objectives of this research were to develop the coaching guidelines for the teacher at the destination school to enhance distance learning television (DLTV) of learner and to investigate the effectiveness of coaching for the teacher at the destination school to enhance DLTV of learners. The research was divided into five phases consisting of the study of significant and essential general information, coaching drafting, coaching quality inspection, an inspection of coaching efficiency, and inspection of coaching effectiveness. The qualitative research method was applied to collect data and test coaching effectiveness that included the interview and observation on the teacher's coaching behaviour, learning and communication behaviour of the learner. The collected data were analyzed by the content analysis method. Research results showed that the coaching model to enhance distance learning television management for the teachers at the destination schools named the PDP model. It comprised of three components classified by the learning duration: pre-learning, during learning and post-learning. Test results of DLTV effectiveness for the teacher at the destination school illustrated. Results can be put into practical context to create new distance learning courses for other elementary schools.
\end{abstract}

Keywords: Self-learning, DLTV, Self-discipline, Instructional coaching

\subsection{BACKGROUND AND SIGNIFICANCE}

The learners in the new era have the potential to access knowledge via different methods to pursue knowledge that they are interested in freely. Various patterns of learning are available, such as the learner and teacher, self-learning, learning from online media, or the distance learning television. Distance learning television or DLTV in Thailand context is the learning where the learner at the destination location learns the same concepts and activities with the learner at the original source. The teacher at the original source manages the learning while the teacher at the destination location promotes, supports, advises, and facilitates the learner to achieve the objectives of DLTV (Distance Learning Foundation under the Royal Patronage, 2020). 


\section{International Journal of Social Sciences and Management Review}

The key supportive factors for the success of DLTV not only fall on the teacher at the origin source, the efficient transmission system and the teacher manual but also the teacher at the destination school who develops the learner's learning as they are very close to them. The significant roles of the teacher at the destination school include preparing the learner, arranging the tools, equipment and venue, offering help to the learner during DLTV, and giving suggestions and additional assistance to the learner in order to construct learning (Distance Learning Foundation under the Royal Patronage, 2020).

Past research on distance learning in elementary school has found that teaching method should be introduced into the e-learning curricula for primary school so that it provides a more intimate communication between the student and the teacher during classes (Burdina et al., 2019). In addition, the potential of distance education has depended on the abilities to engage in coursework at a self-determined pace and an ability to repeatedly review recorded lectures, 3D simulations, educational YouTube videos, and classmate blog entries on a single platform can be an incredibly helpful tool for learning (Sanguinetti, 2018), also the quality of the teaching is an important factor influencing student satisfaction.

However, no research has been found on the coaching role of destination school teachers that the major question of this study. The literature review found that the key role of the teacher at the destination school is not to set the lesson plan, as the teacher at the origin source, but to coach the destination, learner to construct learning from the pre-learning, during learning and post-learning phase. Coaching of the teacher at the destination school emphasizes efficient preparation prior to DLTV and the inspiration to the learner. During DLTV, the teacher shall feed up the learner, check their understanding, give them feedback, and feed-forward for their self-learning (Costa \& Garmston, 2002; Knight, 2009; Sweeney, 2011; Marzano \& Simms, 2012; Sobel \& Panas, 2012). This research aimed to study the coaching of the teacher at the destination school would uphold the success of DLTV.

\subsection{OBJECTIVES}

To develop the coaching guidelines for enhancing students self-access learning for the teachers at the destination school to enhance the DLTV and investigate the effectiveness of the coaching for the teachers at the destination schools to enhance the DLTV of the learner.

\subsection{SCOPE OF RESEARCH}

\subsection{Informants}

There were 7 directors of the destination primary schools in Kanchanaburi and Suphanburi respectively that are implementing DLTV, 22 teachers from the destination primary schools in Kanchanaburi and Suphanburi respectively that are implementing DLTV, and 163 learners, who are studying grade 5 and 6, from the destination primary schools in Kanchanaburi and Suphanburi province in Thailand respectively that are implementing DLTV.

\subsection{Variables}




\section{International Journal of Social Sciences and Management Review}

Volume: 04, Issue: 02 "March - April 2021"

ISSN 2582-0176

Effectiveness of coaching for the teachers at the destination schools to enhance DLTV comprised of the effects on the teacher and learner at the destination school after the implementation of the coaching guidelines.

\subsection{RESEARCH METHODOLOGY}

Phase 1 The study of the important and necessary primary information for developing coaching guidelines for the teachers at the destination schools to enhance DLTV. Documents and researches related to DLTV were synthesized, which involved the Distance Learning Television Manual for Destination Schools, Distance Learning Television Project, grade 1 to 6, Wang Klai Kangwon School, documents and researches related to coaching in the learning context, relevant concepts and theories about learning involving Theories of Motivation, Reinforcement Theory, Theory of Learning, and Principle of Teaching by Robert Gange', as well as the feed-up with information to accelerate learning, checking the understanding of the learners, the application of the power questions, giving feedback, feed-forward for further the learning, and the interview with the experts at learning about the relevant aspects to the coaching guidelines for DLTV.

Phase 2 It was the drafting of coaching guidelines for the teachers at the destination schools to enhance DLTV based on the study results of documents, concepts and theories that indicated the three phases of coaching. The pre-learning phase was the coaching practice for preparation before DLTV. During learning, phase was the coaching practice of the teachers at the destination schools during DLTV from the beginning of the class until the learning finished. The post-learning phase was the coaching practice after class for the teachers at the destination schools.

Phase 3 It was the quality inspection of the coaching guidelines for the teachers at the destination schools to enhance DLTV in terms of the clarity processed by five teacher representatives from the destination schools. The results showed that some messages conveyed unclear meaning, such as feed-up, checking for understanding, power questions, and feed-forward. The wording was revised by the researcher and rechecked by the representatives.

Phase 4 It was the efficiency inspection of the coaching guidelines for the teachers at the destination schools to enhance DLTV in three aspects: the clarity, the usefulness and the feasibility of implementing the coaching guidelines for the teachers at the destination schools to enhance DLTV. The coaching guidelines was examined by seven teachers from three primary schools in Suphanburi that were implementing DLTV and were not the informants by using the 5-rating scale questionnaire. Results indicated that the clarity, usefulness and feasibility of implementation of the coaching guidelines for the teachers at the destination schools to enhance DLTV was at a high level ( was 4.03-4.48 and SD. was 0.19-0.51).

Phase 5 It was the effectiveness inspection of the coaching guidelines for the teachers at the destination schools to enhance DLTV in terms of the effects on the teachers and learners at the destination schools after the implementation. The coaching guidelines were implemented by 22 teachers in three primary schools in Suphanburi and Kanchaburi. Data were collected 


\section{International Journal of Social Sciences and Management Review}

Volume: 04, Issue: 02 "March - April 2021"

ISSN 2582-0176

using quantitative method by rating scale questionnaire. The first questionnaire was a questionnaire for data gathering about teachers' knowledge and skills before and after implementing the PDP model. It composed of 5 dimensions such as knowledge about the main concepts of learning management and was able to set the consistent lesson plan with DLTV, coach the learner individually during DLTV, handle the class while the learners were performing DLTV, evaluate the learner's learning, and reflect the learning results to the learners. The reliability of this questionnaire computed by alpha coefficient was 0.89 . The other one was a questionnaire for data gathering about learners' skills before and after implementing the PDP model. It composed of 4 dimensions such as set their own goal of each DLTV, performed the learning, learning the main concepts, and thinking ability and desired attributes during DLTV. The reliability of this questionnaire computed by alpha coefficient was 0.85 . Data analyzing conducted by the mean, standard deviation (SD), and ttest for dependent sample.

\subsection{RESULTS}

\subsection{Development results of coaching guidelines for students to enhance self-access learning were as follows.}

Pre-learning phase, it was the practice to prepare for DLTV each time which included:

1. Study the lesson plan in the DLTV Manual focusing on the main concepts, process and activities, and evaluation.

2. Study the main concepts in-depth for the accurate and precise understanding, and arrange the material, equipment and venue for performing learning activity as required by the lesson plan.

3. Prepare the learner by informing the learning schedule, core concepts and activities.

4. Create inner motivation for the learner by emphasizing the benefits of what they were learning and introducing the challenging activities.

During the learning phase, it was the practice from the beginning of the class before the broadcasting, during broadcasting, until the class finished. The practice consisted of four components.

Feed-up the learner

1. Review the main concepts which were fundamental to learning.

2. Introduce the learning objectives and tasks.

3. Activate the learner's inner motivation.

4. Build up confidence and pride in the learner.

Checking understanding of the learner during learning

1. Monitor the learner's behaviour during the activity.

2. Query the individual learner who was likely to fall behind.

3. Check the learner performance during the activity. 


\section{International Journal of Social Sciences and Management Review}

Volume: 04, Issue: 02 "March - April 2021"

ISSN 2582-0176

4. Assist the learner who fell behind with the appropriate method.

Apply the power questions

1. Ask a question to activate the advanced thinking that was related to the lesson.

2. Use different questions that suited the learner's ability.

3. Apply techniques to encourage the learner to find the right answer.

4. Value the learner's answer and encourage the one who answered the question.

Feedback and Feed-forward

1. Summarize the main point with the learner.

2. Give feedback on the learner's strength and weak points for improvement.

3. Suggest the improvement and development to the learner.

4. Encourage the learner to learn and continue the development.

The post-learning phase was the practice after class which included:

1. Evaluate the learning of each learner focusing on knowledge, learning process and attributes evaluation.

2. Reflect the evaluation results to the development of each learner and encourage them to further the learning by themselves.

3. Process the lesson learned about the factors supporting the success of DLTV and record the efficient practice in order to apply to the self-created DLTV context.

4. Improvement the learners according to the learning outcomes.

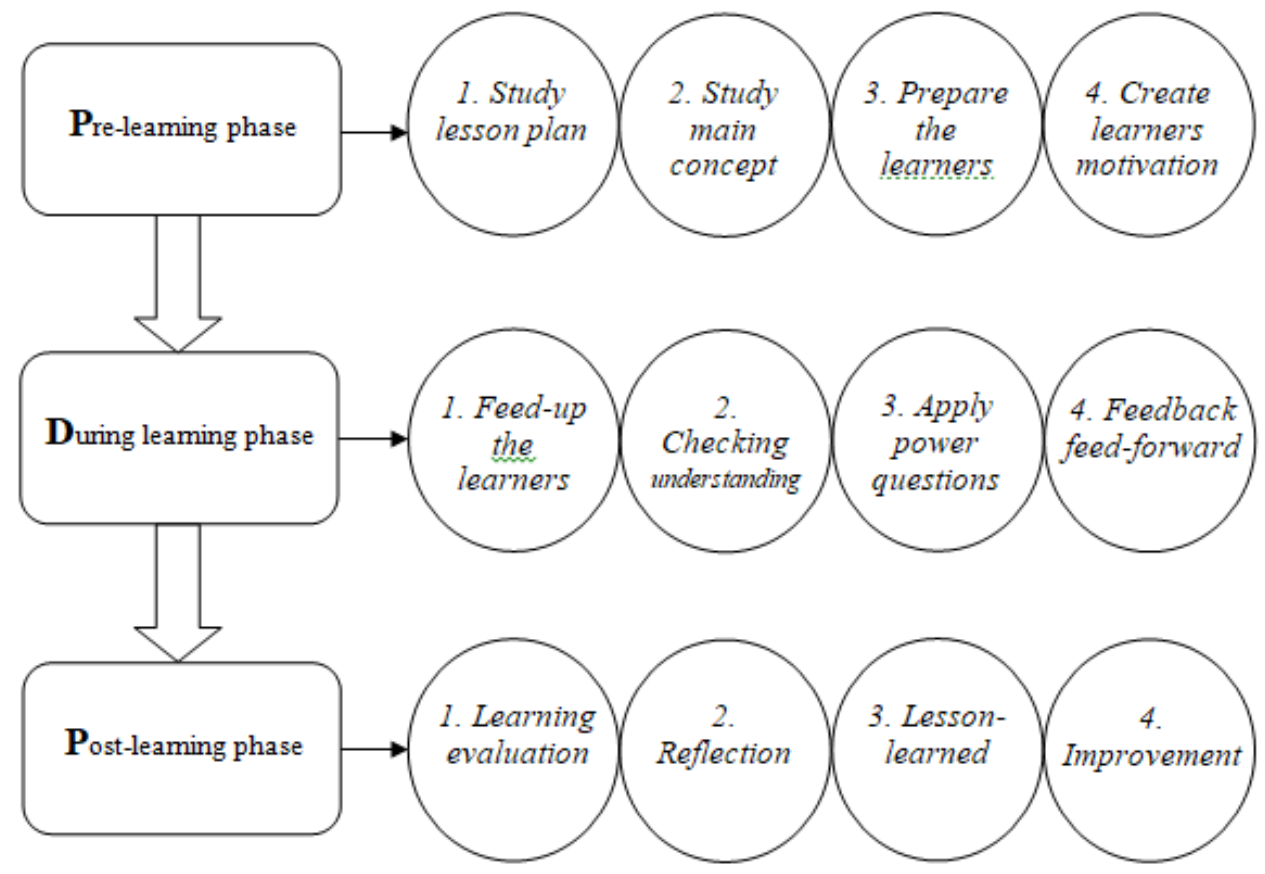

Figure 1. PDP model: Coaching Model to Enhance Students self-access in Distance Learning Television Management 


\section{International Journal of Social Sciences and Management Review}

Volume: 04, Issue: 02 "March - April 2021"

ISSN 2582-0176

5.2 Effectiveness inspection results of coaching guidelines for the teacher at the destination school to enhance DLTV were as follows.

\subsubsection{Effects on the teacher}

5.2.1.1 The teacher had knowledge about the main concepts of learning management and was able to set the consistent lesson plan with DLTV that was in accordance with the learning at the origin source efficiently after implementing the model higher than before statistically significant at .01 according to the table 1 .

Table 1. Teachers' knowledge before and after implementing the model

\begin{tabular}{llllll}
\hline Testing & $\bar{X}$ & SD. & t & df. & Sig. \\
\hline Before & 14.64 & 1.22 & \multirow{2}{*}{17.89} & 21 & .000 \\
After & 20.64 & 1.05 & & & \\
\hline
\end{tabular}

5.2.1.2 The teacher was able to coach the learner individually during DLTV by using the power questions, giving assistance and suggestions so the learner was able to learn and construct learning as required after implementing the model higher than before statistically significant at .01 according to table 2 .

Table 2. Teachers' coaching skills before and after implementing the model

\begin{tabular}{llllll}
\hline Testing & $\bar{X}$ & SD. & t & df. & Sig. \\
\hline Before & 12.50 & 1.10 & 31.91 & 21 & .000 \\
After & 20.18 & 0.73 & & & \\
\hline
\end{tabular}

5.2.1.3 The teacher was able to handle the class while the learners were performing DLTV to facilitate them to learn step by step at the same time with the origin source after implementing the model higher than before statistically significant at .01 according to table 3 .

Table 3. Teachers' ability to handle the class before and after implementing the model

\begin{tabular}{llllll}
\hline Testing & $\bar{X}$ & SD. & $\mathrm{t}$ & $\mathrm{df}$. & Sig. \\
\hline Before & 12.68 & 1.89 & \multirow{2}{*}{19.07} & 21 & .000 \\
After & 20.18 & 1.30 & & & \\
\hline
\end{tabular}

5.2.1.4 The teacher was able to evaluate the learner's learning performance systematically aiming to evaluate the concept, learning process and desired attributes in order to create the information and apply the evaluation results to develop the learner after implementing the model higher than before statistically significant at .01 according to the table 4 .

Table 4. Teachers' ability of evaluate before and after implementing the model 


\section{International Journal of Social Sciences and Management Review}

Volume: 04, Issue: 02 "March - April 2021"

ISSN 2582-0176

\begin{tabular}{llllll}
\hline Testing & $\bar{X}$ & SD. & t & df. & Sig. \\
\hline Before & 13.27 & 1.39 & \multirow{2}{*}{17.05} & 21 & .000 \\
After & 19.68 & 1.04 & & & \\
\hline
\end{tabular}

5.2.1.5 The teacher reflected the results to continuously improve and develop the capability of being the teacher at the destination school from the lesson learned after implementing the model higher than before statistically significant at .01 according to table 5 .

Table 5. Teachers' ability to reflection before and after implementing the model

\begin{tabular}{llllll}
\hline Testing & $\bar{X}$ & SD. & $\mathrm{t}$ & $\mathrm{df}$. & Sig. \\
\hline Before & 10.59 & 1.37 & \multirow{2}{*}{16.53} & 21 & .000 \\
After & 18.50 & 1.41 & & & \\
\hline
\end{tabular}

\subsection{Effects on the students}

5.3.1 The students set their own goal of each DLTV and prepared themselves before learning after implementing the model higher than before statistically significant at .01 according to table 6.

Table 6. Students' ability to setting their own goal before and after implementing the model

\begin{tabular}{llllll}
\hline Testing & $\bar{X}$ & SD. & t & df. & Sig. \\
\hline Before & 10.36 & 1.17 & \multirow{2}{*}{34.90} & \multirow{2}{*}{162} & .000 \\
After & 14.72 & 1.12 & & & \\
\hline
\end{tabular}

5.3.2 The students performed the learning that was consistent with that of the original source efficiently after implementing the model higher than before statistically significant at .01 according to table 7 .

Table 7. Students' performed the learning before and after implementing the model

\begin{tabular}{llllll}
\hline Testing & $\bar{X}$ & SD. & t & df. & Sig. \\
\hline Before & 11.17 & 1.06 & \multirow{2}{*}{30.99} & 162 & .000 \\
After & 14.64 & 1.03 & & & \\
\hline
\end{tabular}

5.3.3 The students learned the main concepts by themselves accurately or had been coached individually until having the accurate learning after implementing the model higher than before statistically significant at .01 according to the table 8 .

Table 8. Students' learned the main concepts before and after implementing the model 


\section{International Journal of Social Sciences and Management Review}

Volume: 04, Issue: 02 "March - April 2021"

ISSN 2582-0176

\begin{tabular}{llllll}
\hline Testing & $\bar{X}$ & SD. & $\mathrm{t}$ & df. & Sig. \\
\hline Before & 10.71 & 0.91 & \multirow{2}{*}{41.58} & 162 & .000 \\
After & 14.51 & 0.77 & & & \\
\hline
\end{tabular}

5.3.4 The students had been developed thinking ability and desired attributes during DLTV after implementing the model higher than before statistically significant at .01 according to the table 9.

Table 9. Students' thinking before and after implementing the model

\begin{tabular}{llllll}
\hline Testing & $\bar{X}$ & SD. & $\mathrm{t}$ & $\mathrm{df}$. & Sig. \\
\hline Before & 10.66 & 1.08 & \multirow{2}{*}{37.65} & \multirow{2}{*}{162} & .000 \\
After & 14.72 & 0.78 & & & \\
\hline
\end{tabular}

\subsection{DISCUSSION}

Research results indicated the three phases of the coaching guidelines for distance learning television or DLTV enhancement, which were pre-learning, during learning and post-learning phase, because the researcher had analyzed the components of DLTV which required efficient preparation prior to learning in terms of content, activities and equipment to be consistent with DLTV lesson plan. Moreover, the teacher had to promote, support, facilitate, and coach the students using the coaching techniques that fulfilled the demand of each student. After learning, the teacher evaluated the learning performance and reflected the evaluation results for the improvement and development of the students. It was in line with the Distance Learning Television Project, Wang Klai Kangwon School that determined the practice for the teacher at the destination school (Distance Learning Foundation Under the Royal Patronage, 2020).

Phase 1 of coaching guidelines emphasized the study on the lesson plan in the DLTV Manual focusing on the core concepts, learning process and activities, learning evaluation, as well as the study on additional knowledge related to the core concepts for the precise and accurate understanding. Further, it focused on the provision of materials, equipment and venue for learning as required by the lesson plan. The students were informed about the learning schedule, core concepts and learning activities, and encouraged the inner motivation by pointing out the benefits of learning and challenging activities. It was obvious that the preparation of the teachers at the destination schools was significant and essential for the efficient DLTV, particularly the preparation of the learning concept, activities leading to such concept and equipment and materials for learning. Besides, the preparation of learning exchange of the students was crucial in order to construct efficient learning. It was consistent with the Action Learning Theory by Marquardt (1999) which focused on the student to shape the learning (Learning: L) by performing the learning based on the activity containing the accurate and complete concept (Performance: P), answering the questions that activated thinking (Questioning insight: Q) related to the content and learning process. In addition, the information about DLTV provided to the students by the teacher at the destination school was one of the essential factors that created meaningful learning and promoted learning 


\title{
International Journal of Social Sciences and Management Review
}

\author{
Volume: 04, Issue: 02 "March - April 2021"
}

ISSN 2582-0176

efficiency. David Paul Ausubel, the American psychologist who developed the Theory of Meaningful Verbal Learning believed that learning would be meaningful if it connected to what the learner had learnt. Any content could be arranged for the students if the appropriate method was applied to suit the individual students when they were ready to learn (Ausubel, 2000). Regarding the learning motivation, it was the process that the teacher at the destination school should construct for the students prior to DLTV. The motivation was the influential factor of learning because if the students were motivated, they would strive to learn and achieve success. Theories of Motivation by David I. McClelland explained that the motivation forcing the individual to make an effort to work successfully and achieve the goal comprised of the desire for success, the desire for commitment and the desire for power. When the individual successfully achieved something, it accelerated them to improve themselves further (McClelland, 1961). Thus, the construction of motivation was one of the key missions of the teacher at the destination school.

Phase 2 of coaching guidelines, which was the coaching during DLTV, focused on the feedup, checking understanding of the students, the use of power questions, and giving feedback and feed-forward. It was obvious that the important role of the teacher at the destination school was coaching as they were with the students during learning. The goal of coaching was to help the students to create cognition. Costa \& Garmston (2002), Knight (2009), Sweeney (2011), Marzano \& Simms (2012), and Sobel \& Panas (2012) stated that cognitive coaching was the new form of innovation of learner development that was developed from the teaching and facilitator to the coach and highlighted the mental process to formulate learning skills and methods, self-improvement, and self-learning to the learner, as well as the advance thinking skills which included critical thinking, evaluative thinking and creative thinking. Coaching with feed-up, checking the understanding, power questions, and feedback and feed-forward helped the learner to learn efficiently. It was in line with Patphol (2013) who found out that if the teacher acted as the coach, the learner would learn efficiently and developed their advanced thinking.

Phase 3 of coaching guidelines, which was the post-learning phase, underlined the learning evaluation and reflection of the evaluation for the learner improvement and development, as well as the lesson learned of the teacher at the destination school for the continuing development. It pointed out that evaluation was the significant mission of the teacher at the destination school who evaluated the learning with the quality method and tools and used it to develop the individual learner to achieve the objectives of DLTV by applying the authentic assessment guidelines that would acquire the applicable information for the learner development. It was consistent with the research of Marzano (2000) which showed that the efficient evaluation should be processed with various methods and tools that concerned with what was evaluated. Meanwhile, feedback and feed-forward was the mechanism to facilitate the learner to apply the information in order to develop themselves. Ambrose (2010) mentioned that the feedback that made the learner realized what they should improve was the tool for their self-development. Moreover, the lesson learned of the teacher at the destination school after each class was crucial for the development of coaching efficiency of the teachers themselves since the lesson learned formulated the applicable knowledge for selfdevelopment as it was generated from the action. DeGosky (2005) stated that the lesson 


\title{
International Journal of Social Sciences and Management Review
}

\author{
Volume: 04, Issue: 02 "March - April 2021"
}

ISSN 2582-0176

learned after practice would construct knowledge to the practitioner to improve and develop works continuously.

In terms of the effectiveness of coaching on the teacher, the research results showed that if the teacher understood the main concept of the lesson plan, DLTV would be consistent with the learning at the origin source. The teacher studied the main concept from DLTV Manual in order to coach the learner during DLTV efficiently. Besides, coaching the learner during DLTV was a chance for the teacher to learn the concept simultaneously with the learner. For this reason, the teacher had an in-depth understanding of the main concept. The researcher constructed the inner motivation of the teachers at the destination schools by pointing out the significance of DLTV. It was in accordance with the Adult Learning Theory developed by Knowles (1984) which explained that the adult applied inner motivation rather than external motivation to support learning. For this reason, the adult exercised their self-potential in learning fully. In addition, some research results indicated that the teacher was able to coach the individual learner during DLTV by using the power questions, providing assistance and advice so the learner could keep up with learning. Moreover, the teacher was able to handle the class while the learners were attending DLTV and following up with the learning at the same time with the origin source. Furthermore, the teacher would evaluate the learner's learning performance systematically by emphasizing the learning concept, learning process and skills, and the desired attributes of the learner to gather the information and apply the evaluation results to develop the individual learner and reflect on themselves to improve and develop the capability of being the teacher at the destination school. It was the results of the briefing meeting about coaching the learner in DLTV and the coaching training, as well as the on the job training, provided to the teacher at the destination school regarding the five roles of coaching: feed-up information to activate learning, using power questions, checking to understand of the learner, giving feedback, and feedback and feed-forward. The teacher applied knowledge and coaching skills for DLTV to the actual practice with the learner constantly which finally constructed the ability to manage the classroom by using relevant techniques to the context of each DLTV. Furthermore, the teachers had been trained to evaluate the learning performance and give feedback to develop the learners based on the development and practice process, as well as exchange the learning with other teachers and executives who provided support and assistance. Additionally, the teachers had learnt about the techniques for giving feedback from the teacher at the origin source, which was in line with the Action Learning Theory by Marquardt (1999) that focused on the construction of learning (Learning: L) by performing the learning based on the activity containing the accurate and complete concept (Performance: P), answering the questions that activated thinking (Questioning insight: Q) which was in accordance with the main concept and learning process $7 \mathrm{E}$ with the reflection (Reflection: $\mathrm{R}$ ) and implementation leading to learning (Implementation: I).

In regard to the effectiveness of coaching on the learner, the research results illustrated that the learner set the goal for each DLTV and be prepared for learning. It was because the teacher informed the objectives and activity before DLTV started, as well as provided the information to encourage the learning. When the learner recognized the clear objectives and activities, they had the goal for their learning and planned their learning to perform it efficiently. The results also showed that the learner performed the learning in accordance 


\section{International Journal of Social Sciences and Management Review}

with that of the original school efficiently. This was because the teacher and learner were well-prepared so the learner knew about the activity and prepared the required materials and equipment. Such preparation facilitated the learner to have self-management to perform learning at the same time as the origin school. It was in line with the Theory of Meaningful Verbal Learning developed by David Paul Ausubel, the American psychologist who believed that the learning would be meaningful if the learner connected it with what they had learnt. Moreover, the concepts might be set for the learner via the technique that suited the learner potential when they were ready to learn. Moreover, Ausubel invented an advanced organizer as the cognitive instructional strategy that added more meaning to the content so the learner viewed the overview and connection of the concept before learning in order to link the current and new knowledge (Ausubel, 1963).

Nevertheless, another significant discovery was that the learner learned the main concept by themselves accurately. The learner also had advance thinking skills which was the result of the individual coaching from the teacher and performed the learning activity at the same time with the origin school. The teacher at the destination school was the coach who assisted and facilitated the efficient learning, as well as evaluated the learning performance and reflected the evaluation results constantly. Besides, the teacher at the destination school helped the learner who fell behind or misunderstood individually. Further, the research results revealed that the desired attributes of the learner had been developed during DLTV because they were learning with their classmates under the supervision of the teacher at the destination school. The most outstanding developed attributes were self-discipline, generosity and team building. It was consistent with Whitmore (2002), Wilkins (2000), Hargrove (2003), and Hurd (2002) who stated that coaching efficiently enhanced the efficiency of work and learning, and promoted the learner to achieve the learning successfully by applying various methods, such as listening, dialogue and etc. Additionally, a good coaching process would help the learner to achieve the goal of learning.

\subsection{LIMITATION}

The limitations of this study were small sample size that maybe influenced the generalizability and applications to practice. Those who will use the PDP model should adapt to the context and situation.

Recommendations

\subsection{Recommendation for the application of the research results.}

1. The teacher at the destination school should study the concepts, principles and guidelines for coaching for DLTV enhancement for the teachers at the destination schools for more understanding in order to perform coaching efficiently.

2. The teacher at the destination school should apply the coaching technique to suit the learning context, such as the nature of the learner, learning concepts and facilitative resources.

3. The school administrators who are implementing DLTV should promote and support the teacher to apply the coaching method to each phase efficiently. 


\section{International Journal of Social Sciences and Management Review}

Volume: 04, Issue: 02 "March - April 2021"

ISSN 2582-0176

\subsection{Recommendations for further researches}

1. The developed coaching guidelines for DLTV enhancement for the teacher at the destination school should be set as the training course for the teacher at the destination school to be capable of being a coach for DLTV.

2. The developed coaching guidelines for DLTV enhancement for the teacher at the destination school should be studied what are the main emphases of each department that the teacher should coach the learner in order to learn DLTV efficiently.

\section{REFERENCES}

Burdina, G. M., Krapotkina, I. E., \& Nasyrova, L. G. (2019). Distance learning in elementary school classrooms: An emerging framework for contemporary practice. International Journal of Instruction, 12(1), 1-16.

Ambrose, S. A., \& Other. (2010). How learning works: 7 research-based principles for smart teaching. Josey-Bass.

Ausubel, D. P. (1963). The psychology of meaningful verbal learning. Grune and Stratton.

Ausubel, D. P. (2000). The acquisition and retention of knowledge: A cognitive view. Kluwer Academic Publishers

Costa, A. L., \& Garmston, R. J. (2002). Cognitive coaching a foundation for renaissance schools (2nd ed). Christopher-Gordon Publishers.

DeGosky, M. T. (2005). Improving after action review (AAR) practice. Guidance Group, Inc. Distance Learning Foundation Under the Royal Patronage. (2020). Handbook of DLTV. https://www.dltv.ac.th/content/content-detail/10644/1001

Knight, J. (2009). Coaching approaches \& perspectives. Corwin Press.

Knowles, M. (1984). Andragogy in action: Applying modern principles of adult learning. Jossey-Bass.

Marquardt, M. J. (1999). Action learning in action: Transforming problems and people for world-class organizational learning. Davies-Black.

Marzano, R. J. (2000). Transforming classroom grading. Association for Supervision and Curriculum Development.

Marzano, R. J., \& Simms, J. (2012). Coaching classroom instruction: The classroom strategies series. Marzano Research Laboratory.

McClelland, D. C. (1961). The achieving society. The Free Press. 


\section{International Journal of Social Sciences and Management Review}

Patphol, M. (2013). Teacher development model to enhancing learning management for students' thinking and happiness in learning. Srinakharinwirot University.

Sanguinetti, E. (2018). K-12 distance learning and its effects on academic achievement and student engagement. Governor's Rural Affairs Council.

Sobel, A., \& Panas, J. (2012). Power questions: Build relationships, win new business, and influence others. John Wiley \& Sons.

Sweeney, D. (2011). Student-centered coaching: A quide for K-8 coachers and principles. Corwin Press. 